\section{"Still Forgotten": Perception and Situation of Senior Filipino Gay Men Living with HIV}

Jed Patrick Montero Catalan

Adela Serra Ty Memorial Medical Center

catalan_jedpatrick@yahoo.com
Article Information

DOI:

https://doi.org/10.38192/1.6.3.pnauk.wcc20. ab1

Epub: 11.10 .2020

Abstract presented at Philippine Nurses UK World Café Convention 24 October 2020

Keywords: HIV, Filipino, gay men

Background: In the Philippine context, the proportion of older adults living with Human Immunodeficiency Virus (HIV) is remarkable; yet hitherto has not been actively investigated.

Aim: The paper aims to explore the perceptions of senior Filipino gay men about their HIV status and the situations they experienced living with the infection.

Method: Senior gays, aged 60 to 70 years old, infected with HIV, and living in the selected cities of the Southern Philippines, consented to participate in this exploratory study. A series of in-depth interviews were mainly used to gather data then subjected to content analysis.

Result: The results showed that participants perceive themselves and their situations experienced as hard and full of uncertainties which are characterized by co-morbidity, lack of support, and age-inappropriate services. Most had significant health problems, which may be related to ageing, in addition to their HIV-related symptoms. The subjects expressed their uncertainties on their chances of survival and the adverse effects of their treatment with their fragile body. They face triadic social stigma associated with their sexuality, age, and HIV-status that coerced them to live alone and isolated. Bearing these reasons, they have been denying their condition and hid from seeking further medical assistance. This group also verbalized their frustrations to the government and health authorities of being forgotten. These are rooted in lack of access to healthcare services appropriate to their age and misrepresentations, unlike their HIV-positive younger counterparts.

Conclusion: The cases illustrated in this paper represent the huge gap and struggles that senior Filipino gay men living with
HIV are facing toward equity to sexual health rights. The findings suggest the need to develop a policy framework and a program that focuses on HIV-positive elderly LGBTIQ+. And, conduct further studies on how these experiences may vary by ethnicity and sexual orientations hence identify more issues related to HIV and ageing.

Funding: Philippine Nurses Association - BIBAHILITA Chapter

Declaration of Conflict of Interest: None

\section{References}

- Choi, S.K., and I.H. Meyer. 2016. LGBT Aging: A Review of Research Findings, Needs, and Policy Implementation. Los Angeles: The William Institute.

https://williamsinstitute.law.ucla.edu/wpcontent/uploads/LGBT-Aging-A-Review.pdf.

- $\quad$ Lim, F., and J. Pace. 2013. "Caring for Older Lesbian, Gay, Bisexual, and Transgender Adults." American Nurse Today 8(1).

https://www.americannursetoday.com/caring-for-olderlesbian-gay-bisexual-and-transgender-adults/.

- Motilla, R. 2006. "Correlates of an Affirmative Gay Identity among Older Gay Men." Faculty Research., Philippines: Miriam College - Women and Gender Institute.

- Nadal, K., and M. Corpus. 2012. "Tomboys' and 'Baklas": Experiences of Lesbian and Gay Filipino Americans." Asian American Journal of Psychology 4(3): 166-175. doi: 10.1037/a0030168.

- United Nation Development Program, United States Agency for International Development. 2014. "Being LGBT in Asia: The Philippines Country Report". UNDP. https://www.usaid.gov/sites/default/files/documents/18 61/2014.pdf 